\title{
A Survey of COVID-19 Pandemic-related lockdown on the Lifestyle of Secondary School Students in the UK
}

Letter

Abstract:

Background: We explored the impact of COVID-19 pandemic imposed lockdown on the lifestyle (physical, mental, dietary habits, development of new skills and behaviour) of secondary school students in an urban state all-girls school in Birmingham, United Kingdom.

Methods: An online survey using Google forms distributed online via the School Newsletter - comprising 40 questions on sleep, dietary habits, physical activity, mental health, new skills and COVID-19 symptoms. Responses were sought from pupils in school years 7-12, corresponding to age 11-18 years, (approximately 1099 students).

Results: There were 102 responses received, a response rate of $10 \%$.

- $\quad$ Sleep - students slept for an additional two and half hours during lockdown, and 90 minutes extra during the period of attending school online.

- $\quad$ Physical activities - compared to 3-hours a day during regular school time, mean daily physical activity dropped to 1-3 hours per week for $60 \%$ of students during lockdown, which were mainly home workouts, walking and cycling.

- Skills - while 54\% reported deterioration in academic performance, 33\% learnt a new skill such as baking or a new language.

- Mood - one third of students felt negative and $45 \%$ felt more argumentative.

- $\quad$ Food \& shopping - majority (60\%) reported both increased snacking as well as fresh fruit consumption. 30\% families had changed to online grocery shopping. 1 in 5 students reported the need to ration their food.

- Covid-19 symptoms - 1 in 4 students reported symptoms of COVID-19 infection

Conclusion: Our results exploring the impact of the pandemic on a girls secondary school pupils presents a mixed picture; On the one hand there is a positive impact on sleep, learning new skills and change in diet. However there is also the adverse impact on reduced physical activity, academic performance, mood, in social interactions and the economic necessity to ration food. More information is needed to explore the longer term impact of the pandemic on education, health and the interventions that may mitigate this.

Keywords: Coronavirus, COVID-19, Secondary school students, Lifestyle, physical, mental
Nithyashree Kumaresan 12 M, Shukrithi Kumaresan 7X

King Edwards VI Camphill School for Girls, Birmingham, UK

Correspondence to: v.ridley@kechg.org.uk - Ms. Victoria Ridley, Head of Year 10 and Chemistry Teacher at King Edward VI Camp Hill School for Girls

Cite as: Kumaresan, N., Kumaresan, S. (2022) A survey of COVID-19 pandemic related lockdown on the lifestyle of secondary school students in the UK. Sushruta J Health Pol \& Opin vol15; Issue1: 16 ePub 24.1.22 DOI https://doi.org/10.38192/15.1.5

$\underline{\text { Article Information }}$

Submitted 4.10.21

Revised 27.12.21

Published 24.1.22

ISSN 2732-5164 (Online) ISSN 2732-5156 (Print)

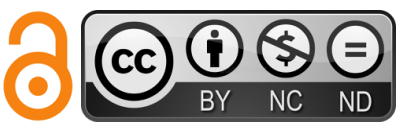




\section{Introduction:}

COVID-19 has made a significant impact to our lifestyle since December 2019. The World Health Organisation (WHO) declared it as a pandemic in March 2020. It has since impacted around 22 million people of which around 4.5 million have succumbed as of September 2021 [1]. In the UK there were three lockdowns impacting the school life of children significantly. This was due to plethora of factors. It was ranging from lack of school meals, inadequate parental support at home, to complete cessation of physical activity and emotional interactions with peers due to imposed social isolation [2]. As a result the key stages of transition from primary to secondary schools were shortened. The school leaving examinations and University examinations were cancelled. Hence secondary school children felt lost due to variable guidance from different authorities, ambiguity over their progression and uncertainty about their future. Despite evidence that school children were not known to be affected to a great extent by COVID-19, schools were closed [3].

We felt that this was an opportunity to explore the impact of the pandemic on the younger generation, which would help schools and families to plan supportive interventions.

\section{Methodology:}

We designed an online survey comprising of 40 questions, using Google Forms. The questions were crafted to assess maintenance of a daily schedule, physical activities, mental wellbeing, and outlook on life, dietary habits, software and gadget use, development of new habits, hobby and motivation. The questionnaire was approved by the School administration in December 2020 and distributed via the newsletter to all the parents of secondary children in our school. Responses were collected between Jan and July 2021. Statistical analysis was done using Google spreadsheet.

\section{Results:}

\section{Study population}

We received 102 responses, a response rate of $10 \%$ (The all-girls school student population was = 1099). Data on ethnicity was not collected. King Edward VI Camp Hill School for Girls is a grammar school for girls aged 11-18 in Kings Heath, a suburb of South Birmingham. There are 1102 pupils currently on roll, most of whom live in the surrounding catchment area (figure 1). [4] The Kings Heath and Brandwood ward, in which the school is located, has a population of 18,948 (2011 census) of which $23.9 \%$ are under 18. [5] This ward has an average employment rate of $70.6 \%$ and $40.7 \%$ have NVQ4+ qualifications (equivalent to adequate undergraduate education/higher apprenticeship). [6] Kings Heath and Brandwood is a diverse ward in comparison to Birmingham and the UK, with $16.6 \%$ and $4.6 \%$ Asian and Black and minority groups respectively compared to $7.8 \%$ Asian and $3.5 \%$ black and ethnic minority groups representing the total UK population. The ward also has the $10^{\text {th }}$ highest average income rate of all the Birmingham city wards. [5]

Sleep

Students reported a mean sleep period of $6 \mathrm{~h} 30 \mathrm{~min}$ during regular school days, which increased by two and half hours to 9 hours during the period of lockdown, but reduced down to around $7 \mathrm{~h} 30 \mathrm{~min}$ during periods of online lessons.

\section{Outdoor Activities}

Sixty six percent pupils felt their physical activity was reduced during lockdown. Students left house around once or twice a day during the lockdown, increasing to a mean 3-4 during the summer months. Compared to $54 \%$ of students spending more than 3-hours in physical activity during regular school-time, $63 \%$ of students spent only 1 3 hours per week, during the lockdown. The most popular activities were workout at home (40\%), walking (27.5\%) and cycling (11\%).

Mental Health \& Social Interactions

- Whilst 34\% felt their mood became more negative, $31 \%$ felt positive, $26 \%$ of responders were unsure and $9 \%$ reported no change.

- $\quad 45 \%$ felt they became more argumentative.

\section{Additional Skills}

- $22 \%$ picked up baking/cooking as an additional skill, $11 \%$ learnt other languages.

- The remaining cohort learnt a wide array of activities ranging from mechanical skills, to gardening and online webinars. 
Academic Performance

$54 \%$ felt their academic performance was adversely affected. $81 \%$ felt that in-person teaching was better than online sessions.

Diet \& Groceries

- Despite $60 \%$ feeling that their snacking increased during lockdown, 61\% had increased consumption of fresh fruits.

Figure 1: Physical activity amongst respondents
- $20 \%$ reported having to ration food during the lockdown.

- $\quad 28 \%$ did online grocery shopping.

COVID-19

Almost a quarter of respondents experienced COVID-19 symptoms, whilst $14.5 \%$ of their family members also experienced symptoms.

Figure 2: Forms of physical exercise

Did the lockdown restrictions restrict your physical activity?
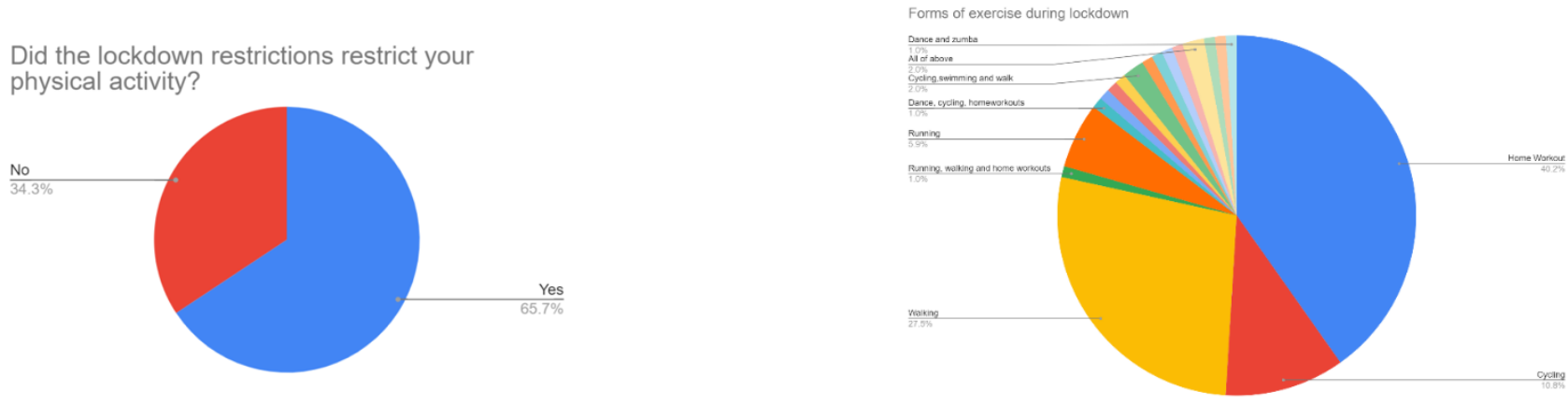

Figure 3a: Change in mood

Figure 3b: Outlook on life

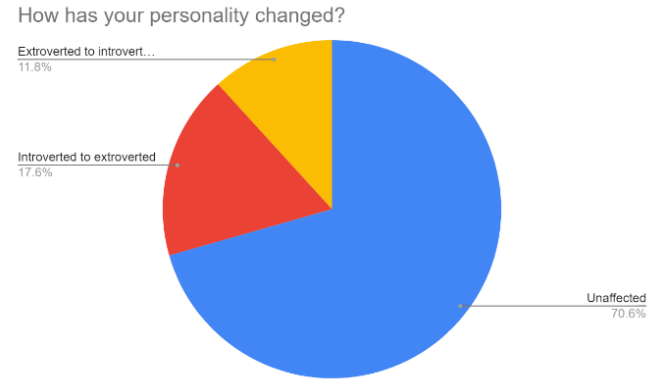

Figure 4: The need for rationing of food during the lockdown

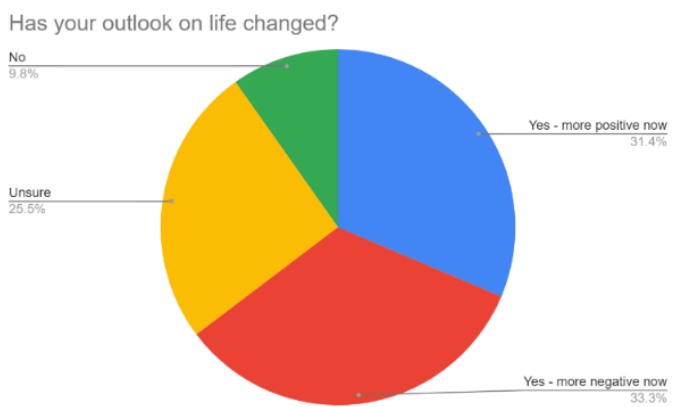

Did you have to ration any food during March -

August 2020?
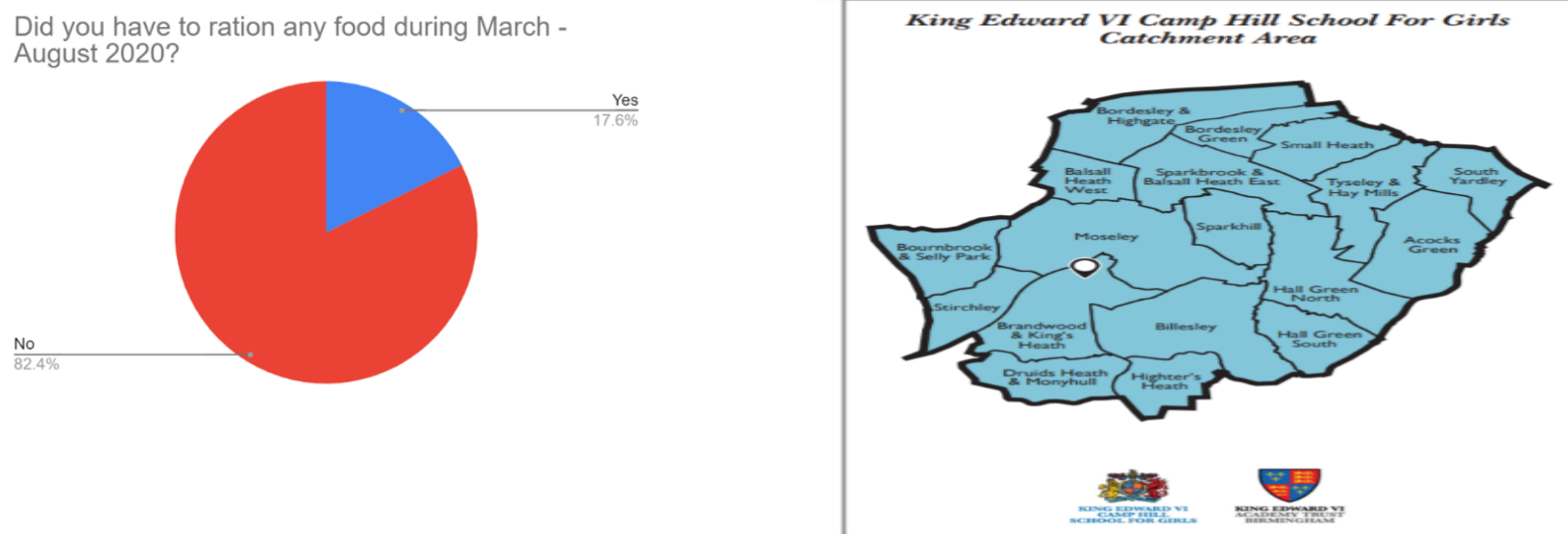

Figure 5 - Catchment Area 


\section{Discussion:}

Our survey explored the impact of the pandemic on lifestyle of secondary school students in an urban, all-girls state school in the midlands, hence our results are likely to allow extrapolation to a much larger cohort in the UK, but the results are unlikely to be applicable to male pupils.

Previous surveys have reported the impact on physical activity as well as mental health[3] but to the best of our knowledge, a holistic assessment of pupillary lifestyle has not been reported widely. Our results indicate a mixed picture for secondary school girls - particularly new starters to secondary school (year 7) and senior school students (years 11, 12 and 13). Academic performance had deteriorated and majority of pupils were not in favour of the online lessons.

The average physical activity of pupils aged 11-17 is 60 minutes or more at least three times a week as per physical activity statistics from the British Heart Foundation survey (BHF 2015). Dunton et al[5] found that physical activity was reduced across the age group of 5-13 years during the first wave in the USA and were concerned that this could result in increase in secondary life style related illnesses like obesity and endocrine disorders. We found that secondary school pupils in our survey also had reduced time for physical activity, increased snacking but improved fresh fruit consumption in their diet.

The average pre-pandemic sleep is between 8-10 hours as recommended by NHS and National Sleep Foundation. Our survey demonstrated that pupils were able to benefit from increasing sleep period from an average $6 \mathrm{~h} 30 \mathrm{~min}$ to the recommended periods. Majority of pupils in our survey did not feel that their mood had changed despite facing a life changing pandemic, perhaps demonstrating a degree of resilience.

Despite multiple studies [6][7] demonstrating that there was lower risk to school children and transmission of virus, the UK administration imposed a total lockdown of schools even after the first wave. According to the UK Office of National Statistics (ONS), $0.42 \%$ of secondary school pupils tested positive for COVID-19 in June 2021 and $10.95 \%$ in November 2020. [8] These numbers differ from the $25 \%$ of our school sample population who tested positive for COVID-19. [9]

Our survey results have a ramification for students who missed taking the school leaving examinations in 2020 so their first ever competitive, externally administered assessment would be the A - levels. We believe that this may have deprived them of a learning experience. The continued disruption to regular assessments in the past 18 months will only augment the anxiety of facing a major external examination.

The limitations of our study are that it is a sample of an all-girls school and our response rates were low. We believe that we would have had more response if it was directly sent to the students.

\section{Conclusions}

Our survey shows how the COVID-19 pandemic and the resulting lockdown impacted on the academic performance and lifestyle, both physically as well as emotionally. One in 4 students had to ration food. But also the ways by which the students found solutions by seeking new skills, compensating by home workouts and improving their sleep and diet. We believe that our results will help school administrations in planning strategies to support pupils with appropriate attention to academic performance, encourage managed physical activities and provide mental wellbeing resources. Attention should also be paid to pupils in families experiencing food poverty, where school meals are crucial.

Declaration: We have no conflict of interest

Reference:

1. Office for National Statistics : SeptemberDecember 2020:Coronavirus and the impact on students in higher education in England:

2. Dunton et al: Early effects of the COVID-19 pandemic on physical activity and sedentary behavior in children living in the U.S; BMC. BMC Public Health (2020) 20:1351

3. Rajmil L, Hjern A, Boran P, et al. Impact of lockdown and school closure on children's health and well-being during the first wave of COVID-19: a narrative review. BMJ Paediatrics Open 2021;5: e001043. doi:10.1136/ bmjpo-2021-001043

4. King Edward VI Camp Hill School for Girls: https://www.kechg.org.uk/_site/data/files/admi 
ssions/38DFDA0D0EEB7B5319DAE73204A65FB

C.pdf (was 4 but changed it to 5 - citations not in correct order??)

5. Birmingham City Council, Kings Heath and

Brandwood Fact Sheet:

file:///C:/Users/mailr/Downloads/Brandwood and Kings Heath Profile\%20(1).pdf

6. Gov.uk, What qualification levels mean,

<https://www.gov.uk/what-different-

qualification-levels-mean/list-of-qualification-

levels>

7. SARS-CoV-2 infection and transmission in educational settings: a prospective, crosssectional analysis of infection clusters and outbreaks in England; Lancet Infect Dis 2021; 21: 344-53

8. 8.ONS COVID-19 Schools Infection Survey <https://www.ons.gov.uk/file?uri=\%2fpeoplepo pulationandcommunity $\% 2$ fhealthandsocialcare $\% 2$ fconditionsanddiseases $\% 2$ fdatasets $\% 2$ fcovid 19schoolsinfectionsurvey\%2fround6pupilantibo dyjune2021/schoolsinfectionsurveydatasets 202 11027.xlsx>

9. 9. Office of National Statistics, COVID-19 Schools Infection Survey, England: Round 6, June 2021, <https://www.ons.gov.uk/peoplepopulationandc ommunity/healthandsocialcare/conditionsanddi seases/bulletins/covid19schoolsinfectionsurvey england/round6june2021>

10. Rajmil L. Role of children in the transmission of the COVID-19 pandemic: a rapid scoping review. BMJ Paediatrics Open 2020;4: e000722. doi:10.1136/ bmjpo-2020-000722

11. Lu X, Zhang L, Du H, et al. SARS-CoV-2 infection in children. N Engl J Med 2020;382:1663-5

12. World Health Organization. Coronavirus disease 2019 (COVID-19): situation report - 50 (https://www.who.int/docs/defaultsource/coronaviruse/situationreports/20200310-sitrep-50-covid19.pdf?sfvrsn=55e904fb)

13. Luca Cristiani, Enrica Mancino, Luigi Matera, Raff aella Nenna, Alessandra Pierangeli, Carolina Scag nolari, Fabio Midulla, Will children reveal their secret? The coronavirus dilemma: European Respiratory Journal Apr 2020, 55 (4) 2000749; DOI: 10.1183/13993003. 00749-2020:

14. A roundup of the latest data and trends about the coronavirus (COVID-19) pandemic from the ONS and other sources, 28 September 2021 